\title{
Specific heat and related thermophysical properties of liquid Fe-Cu-Mo alloy
}

\author{
WANG HaiPeng, LUO BingChi, CHANG Jian \& WEI BingBo ${ }^{\dagger}$ \\ Department of Applied Physics, Northwestern Polytechnical University, Xi'an 710072, China
}

The specific heat and related thermophysical properties of liquid $\mathrm{Fe}_{77.5} \mathrm{Cu}_{13} \mathrm{Mo}_{9.5}$ monotectic alloy were investigated by an electromagnetic levitation drop calorimeter over a wide temperature range from 1482 to $1818 \mathrm{~K}$. A maximum undercooling of $221 \mathrm{~K}\left(0.13 T_{\mathrm{m}}\right)$ was achieved and the specific heat was determined as $44.71 \mathrm{~J} \cdot \mathrm{mol}^{-1} \cdot \mathrm{K}^{-1}$. The excess specific heat, enthalpy change, entropy change and Gibbs free energy difference of this alloy were calculated on the basis of experimental results. It was found that the calculated results by traditional estimating methods can only describe the solidification process under low undercooling conditions. Only the experimental results can reflect the reality under high undercooling conditions. Meanwhile, the thermal diffusivity, thermal conductivity, and sound speed were derived from the present experimental results. Furthermore, the solidified microstructural morphology was examined, which consists of $(\mathrm{Fe})$ and $(\mathrm{Cu})$ phases. The calculated interface energy was applied to exploring the correlation between competitive nucleation and solidification microstructure within monotectic alloy.

high undercooling, specific heat, monotectic alloy, thermophysical property, rapid solidification

The thermophysical properties of undercooled liquid metals and alloys have aroused great research interest in the field of materials physics in recent years ${ }^{[1-6]}$. Specific heat, one of the most important thermophysical properties, has a significant influence on developing the current solidification theory ${ }^{[3-6]}$. Due to the metastable state of undercooled alloy melts, the conventional experimental methods cannot be applied to determining their thermophysical properties. This results in great difficulty to obtain these important data. Therefore, the thermodynamic research of highly undercooled metals and alloys has been in the qualitative or semi-quantitative state.

Up to now, the experimental data for undercooled metals and alloys are still very scarce, although there have been some reports. In the recent literature, only the measurements of some pure metals and simple binary alloys are available. For monotectic alloys, the second liquid phase $\mathrm{L}_{2}$

Received February 11, 2007; accepted May 21, 2007 doi: $10.1007 / \mathrm{s} 11433-007-0044-8$

†Corresponding author (email: bbwei@nwpu.edu.cn)

Supported by the National Natural Science Foundation of China (Grant Nos. 50121101 and 50395105) and the Doctorate Foundation of Northwestern Polytechnical University (Grant No. CX200420) 
always acts as the leading phase to nucleate owing to the lower liquid/liquid interface energy when temperature drops to their monotectic temperatures. Once $\mathrm{L}_{2}$ phase begins to nucleate, the local concentration is favorable for the nucleation of solid phase, resulting in great difficulty to obtain a large undercooling. Therefore, the investigations on the thermophysical properties of monotectic alloys are seriously limited due to the lack of fundamental undercooled data. Electromagnetic levitation can avoid the contamination from crucible walls and obtain a high degree of undercooling. Meanwhile, the drop calorimetric method is applicable to specific heat measurements ${ }^{[4-8]}$.

Fe-Cu-Mo ternary alloy is a typical monotectic system and has a good prospect for industrial applications. The objective of this work is to determine the specific heat of undercooled liquid $\mathrm{Fe}_{77.5} \mathrm{Cu}_{13} \mathrm{Mo}_{9.5}$ ternary alloy using the drop calorimetric method in combination with electromagnetic levitation. The related thermophysical propterties, including the excess specific heat, thermal diffusivity, thermal conductivity and sound speed, are derived on the basis of the experimental results. And their temperature dependence is also revealed by theoretical predictions. Furthermore, the rapid solidification of ternary monotectic alloy is investigated under high undercooling conditions.

\section{Experimental procedure}

$\mathrm{Fe}_{77.5} \mathrm{Cu}_{13} \mathrm{Mo}_{9.5}$ alloy samples were prepared from $99.999 \%$ pure $\mathrm{Fe}, 99.999 \%$ pure $\mathrm{Cu}$ and $99.999 \%$ pure Mo in an arc melting furnace and each sample had a mass of $0.85 \mathrm{~g}$. The experiments were performed by an electromagnetic levitation facility, which was evacuated to $10^{-5} \mathrm{~Pa}$ and back-filled with a mixed gas of argon, helium and hydrogen in the volume ratio of 6:3:1. During the experiment, the sample was levitated and melted by rf induction heating. The temperature was monitored by an infrared pyrometer. A He gas flow refrigerated by liquid nitrogen was blown toward the sample to achieve high undercooling. When an ideal undercooling was attained, the gas flow rate was adjusted to maintain the alloy melt at this undercooling for about $5 \mathrm{~s}$. Then, the power of the rf induction heating was switched off and the levitated sample would drop into an adiabatic copper calorimeter. The temperature difference between the calorimeter shell and the calorimeter block was monitored by a Eurotherm $818 \mathrm{P} 4$ unit. When the temperature of the calorimeter shell was higher or lower than that of the calorimeter block, the resistance heating would begin or stop to ensure that the calorimeter is practically adiabatic. The temperature rise of the adiabatic copper block was measured by Pt100 resistance.

Under adiabatic conditions, after determining the temperature rise of calorimeter block, the enthalpy change of liquid alloy is determined by

$$
H(T)-H(293)=\frac{M}{m} C_{\mathrm{P} 1} \delta T+C_{\mathrm{P} 2}\left(T_{\mathrm{e}}-293\right)+\frac{Q_{\text {lost }}}{m},
$$

where $H(T)$ is the enthalpy of the sample in the superheated or undercooled state, $H(293)$ the reference enthalpy at $293 \mathrm{~K}, T$ the temperature of the alloy sample when dropping, $M$ the mass of calorimeter block, $C_{\mathrm{P} 1}$ the specific heat of calorimeter block which is calibrated as $0.386 \mathrm{~J} \cdot \mathrm{g}^{-1} \cdot \mathrm{K}^{-1}$ in advance, $m$ the mass of the sample, $C_{\mathrm{P} 2}$ the specific heat of the sample at $293 \mathrm{~K}, \delta T=T_{\mathrm{e}}-T_{0}$ the temperature rise of the calorimeter, $T_{\mathrm{e}}$ the equilibrium temperature of the calorimeter, $T_{0}$ the room temperature, and $Q_{\text {lost }}$ the heat loss. This heat loss during dropping cannot be absorbed by the calorimeter, therefore, it should be compensated in eq. (1). Considering the heat loss mainly resulting from thermal convection and heat radiation, $Q_{\text {lost }}$ can be expressed as 


$$
Q_{\text {lost }}=A \varepsilon_{\mathrm{h}} \gamma\left(T^{4}-T_{0}^{4}\right)+A\left(T-T_{0}\right) \int_{0}^{t_{\mathrm{D}}} \alpha_{\mathrm{c}} \mathrm{d} t,
$$

where $A$ is the surface area of the sample, $\varepsilon_{\mathrm{h}}$ the emissivity, $\gamma$ the Stefan-Boltzmann constant, $t_{\mathrm{D}}$ the drop time, and $\alpha_{\mathrm{c}}$ the heat transfer coefficient of the inert gas, which is determined by

$$
\alpha_{\mathrm{c}}=\frac{\lambda_{\mathrm{g}}}{D}\left[2+0.6\left(v_{\mathrm{r}} D \rho_{\mathrm{g}} / \eta_{\mathrm{g}}\right)^{1 / 2}\left(c_{\mathrm{g}} \eta_{\mathrm{g}} / \lambda_{\mathrm{g}}\right)^{1 / 3}\right]
$$

where $\lambda_{\mathrm{g}}$ is the thermal conductivity, $\rho_{\mathrm{g}}$ the density, $\eta_{\mathrm{g}}$ the viscosity, $D$ the diameter of the liquid sample, and $v_{\mathrm{r}}$ the drop velocity.

When the enthalpy change of the sample is determined by eqs. (1)-(3), the specific heat can be derived directly by

$$
C_{\mathrm{PL}}=\frac{\partial[H(T)]}{\partial T}=\frac{\partial[H(T)-H(293)]}{\partial T} .
$$

It can be seen that the specific heat can be obtained just from the temperature rise of the calorimeter without considering the detailed mechanism of phase transformation during solidification.

\section{Results and discussion}

\subsection{Specific heat of undercooled liquid alloy}

The specific heat of liquid $\mathrm{Fe}_{77.5} \mathrm{Cu}_{13} \mathrm{Mo}_{9.5}$ ternary monotectic alloy was determined. According to eqs. (1) - (4), the experimental results of this alloy are presented in Figure 1, which gives the relationship between the enthalpy change and temperature within the temperature range from 1482 to $1818 \mathrm{~K}$. A maximum undercooling of $\Delta T_{\max }=221 \mathrm{~K}\left(0.13 T_{\mathrm{L}}\right)$ was obtained. The enthalpy change shows a good linear relationship with temperature. The following equation can be derived after the regression of the measured data:

$$
H(T)-H(293)=97.96+44.71 T\left(\mathrm{~J} \cdot \mathrm{mol}^{-1}\right) .
$$

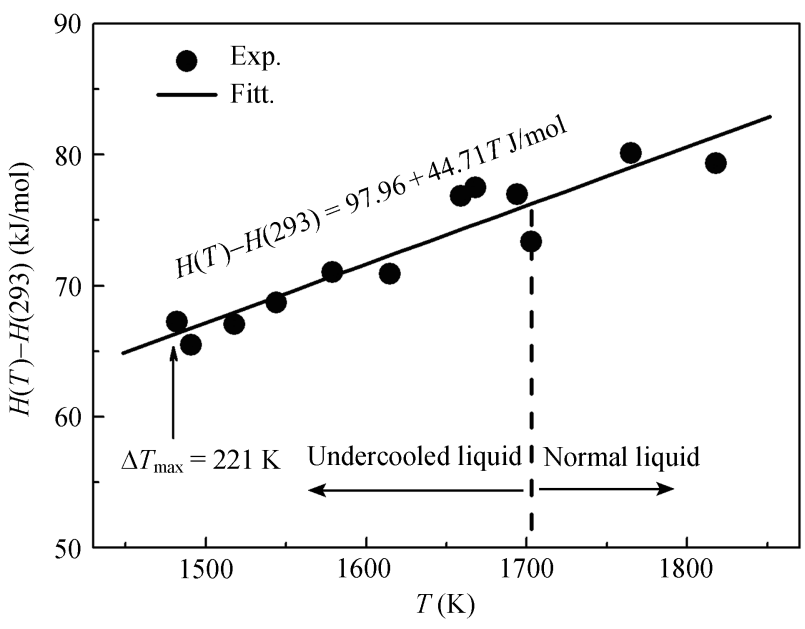

Figure 1 Measured enthalpy difference as a function of temperature.

Accordingly, by the definition of eq. (4), the specific heat of liquid $\mathrm{Fe}_{77.5} \mathrm{Cu}_{13} \mathrm{Mo}_{9.5}$ ternary monotectic alloy in the experimental temperature regime is

$$
C_{\mathrm{PL}}=44.71\left(\mathrm{~J} \cdot \mathrm{mol}^{-1} \cdot \mathrm{K}^{-1}\right) \text {. }
$$


After an extensive survey of the relevant literature, it was found that no reference data is available to be compared with the present experimental results due to great experimental difficulty. For pure $\mathrm{Fe}, \mathrm{Cu}$ and $\mathrm{Mo}$, the specific heat has been measured previously. Their values at melting points are $44.40,31.46$ and $54.69 \mathrm{~J} \cdot \mathrm{mol}^{-1} \cdot \mathrm{K}^{-1}$, respectively. By comparing the specific heat of liquid $\mathrm{Fe}_{77.5} \mathrm{Cu}_{13} \mathrm{Mo}_{9.5}$ ternary monotectic alloy with those of pure $\mathrm{Fe}, \mathrm{Cu}$ and $\mathrm{Mo}$, it is evident that this value is lower than that of pure Mo but larger than those of pure Fe and Cu. According to Neumann-Kopp's rule, the specific heat was also calculated by using the values of pure metals, which is equal to 43.7 $\mathrm{J} \cdot \mathrm{mol}^{-1} \cdot \mathrm{K}^{-1}$. The measured result is a little larger than this approximately estimated result.

Previously, the experimental investigations have been done on pure metals and binary alloys. It revealed generally that, for pure metals with low melting points, the specific heat of undercooled melts increases with the decreasing temperature. This kind of metals includes Bi, In, Sn, etc. ${ }^{[9]}$. Their $C_{\mathrm{PL}}$ values are usually measured by DSC method. $\mathrm{Al}$ is an exceptional case because its $C_{\mathrm{P}}$ value keeps roughly constant although its $T_{\mathrm{m}}$ is not high ${ }^{[10]}$. However, for pure metals whose melting temperatures are higher than $873 \mathrm{~K}$, the specific heat is nearly independent of temperature in a large temperature regime from normal liquid to undercooled state. $\mathrm{Co}, \mathrm{Ni}, \mathrm{Fe}, \mathrm{Zr}$, Mo, etc. belong to this case and the electromagnetic levitation drop calorimeter is frequently employed to measure their $C_{\mathrm{PL}}$ values due to its effective heating and large undercooling. For binary alloys, although the available data are still scarce, some experimental results seem to show a similar temperature-independent variation tendency according to their melting temperatures, such as $\mathrm{Ni}-\mathrm{Cu}, \mathrm{Ni}-\mathrm{Fe}, \mathrm{Ti}-\mathrm{Al}$ and Co-Mo alloys ${ }^{[5-7]}$. $\mathrm{Ni}_{70.2} \mathrm{Si}_{29.8}$ alloy is an exceptional case although its melting temperature is up to $1488 \mathrm{~K}^{[4]}$. For $\mathrm{Fe}_{77.5} \mathrm{Cu}_{13} \mathrm{Mo}_{9.5}$ ternary monotectic alloy, its specific heat is also nearly independent of temperature within the undercooling regime of $221 \mathrm{~K}$ in the experiments. It seems that this is in good agreement with the above inferences. It should be pointed out that the $C_{\mathrm{PL}}$ values of alloys should be the function of composition. Only one alloy was investigated from $\mathrm{Fe}-\mathrm{Cu}$-Mo ternary system in this work, therefore, the relationship between the specific heat and composition of $\mathrm{Fe}-\mathrm{Cu}-\mathrm{Mo}$ alloy should be investigated further. And the temperature dependence of specific heat for ternary alloys should also be given more attention.

Several models have been developed previously to describe the relationship between specific heat and undercooling owing to the limited experimental data on specific heat of undercooled melts. One is the well-known model of Turnbull ${ }^{[11]}$ who proposed that the specific heat value of undercooled melt is approximately equal to that of crystalline solid at the same temperature. The excessive specific heat is, therefore, equal to zero:

$$
\Delta C_{\mathrm{PL}}=0 .
$$

Thompson and Spaepen ${ }^{[12]}$ thought that the excessive specific heat value $\Delta C_{\mathrm{PL}}$ is equal to the ratio of enthalpy difference $\Delta H_{\mathrm{m}}$ divided by the melting point temperature $T_{\mathrm{m}}$ :

$$
\Delta C_{\mathrm{PL}}=\frac{\Delta H_{\mathrm{m}}}{T_{\mathrm{m}}} .
$$

On the basis of the model of Thompson and Spaepen, Battezatti and Garrone ${ }^{[13]}$ gave another equation:

$$
\Delta C_{\mathrm{PL}}=0.8 \times \frac{\Delta H_{\mathrm{m}}}{T_{\mathrm{m}}} .
$$

A further proposal is Dubey-Ramachandrarao's mode ${ }^{[14]}$, which is based on the free volume model of liquids and yields 


$$
\Delta C_{\mathrm{PL}}=\Delta C_{\mathrm{P}}^{\mathrm{m}}\left(\frac{2 T^{3}+3 T^{2} \Delta T-\Delta T^{3}}{2 T^{3}}\right),
$$

where the $\Delta C_{\mathrm{P}}^{\mathrm{m}}$ value is equal to that in eq. (8).

The excessive specific heat was computed as a function of undercooling, as shown in Figure 2. The calculated results by Turnbull, Thompson and Spaepen, and Battezatti and Garrone are equal to $0,9.9$ and $7.9 \mathrm{~J} \cdot \mathrm{mol}^{-1} \cdot \mathrm{K}^{-1}$, respectively. With the increase of undercooling, the results from both experimental data and Dubey-Ramachandrarao's model become larger and larger. Although there exists a deviation of about $4 \mathrm{~J} \cdot \mathrm{mol}^{-1} \cdot \mathrm{K}^{-1}$, the increasing tendencies with undercooling are in good agreement.

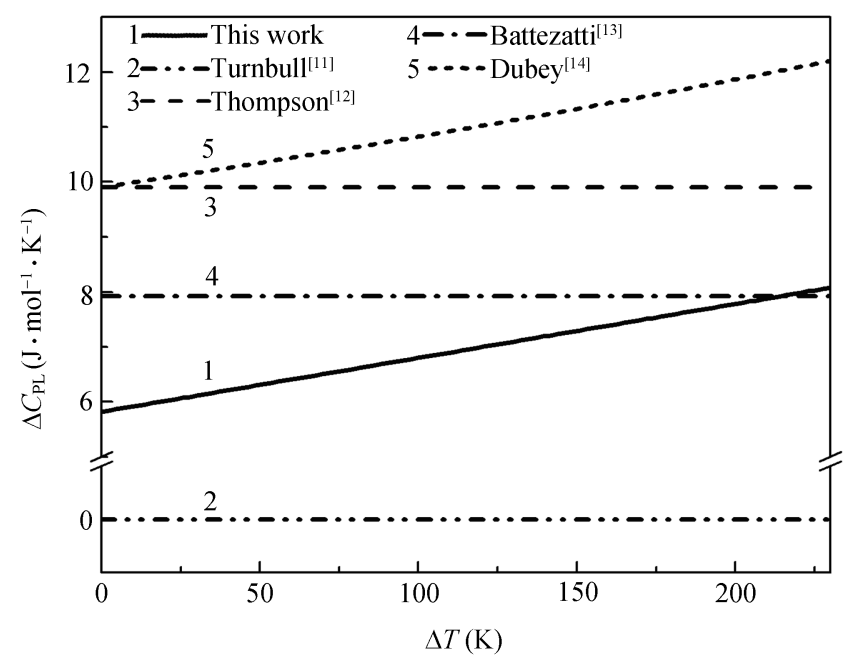

Figure 2 Excessive specific heat versus undercooling.

\subsection{Related thermodynamic properties}

Furthermore, the present measured specific heat of undercooled $\mathrm{Fe}_{77.5} \mathrm{Cu}_{13} \mathrm{Mo}_{9.5}$ ternary monotectic alloy can be applied to computing the relevant thermodynamic properties, such as the enthalpy change $\Delta H_{\mathrm{LS}}$, the entropy change $\Delta S_{\mathrm{LS}}$ and the Gibbs free energy difference $\Delta G_{\mathrm{LS}}$ etc. They are of great importance in the research on crystal nucleation and growth. After determining the specific heat, they are expressed as

$$
\begin{gathered}
\Delta H_{\mathrm{LS}}=\Delta H_{\mathrm{m}}-\int_{T}^{T_{\mathrm{m}}} \Delta C_{\mathrm{PL}}(T) \mathrm{d} T, \\
\Delta S_{\mathrm{LS}}=\frac{\Delta H_{\mathrm{m}}}{T_{\mathrm{m}}}-\int_{T}^{T_{\mathrm{m}}} \frac{\Delta C_{\mathrm{PL}}(T)}{T} \mathrm{~d} T, \\
\Delta G_{\mathrm{LS}}=\Delta H_{\mathrm{LS}}-T \Delta S_{\mathrm{LS}} .
\end{gathered}
$$

According to the experimental results and the above eqs. (11)-(13), the enthalpy change, the entropy change, and the Gibbs free energy difference are calculated as functions of undercooling. The results are given in Figure 3. With the increase of undercooling, $\Delta H_{\mathrm{LS}}$ and $\Delta S_{\mathrm{LS}}$ decrease, whereas $\Delta G_{\mathrm{LS}}$ increases. This reveals that the thermodynamic driving force of phase transformation becomes larger and larger with undercooling. In order to compare the thermodynamic properties derived from the experimental result with those obtained by the previous models, $\Delta H_{\mathrm{LS}}, \Delta S_{\mathrm{LS}}$ and $\Delta G_{\mathrm{LS}}$ are calculated as functions of undercooling. Figure 3 gives the calculated results by 
Turnbull's model as an example, which are shown as the dashed line. With the increase of undercooling, the deviations between the experimental solid line and the approximate dashed line become larger and larger. For $\Delta H_{\mathrm{LS}}$ and $\Delta S_{\mathrm{LS}}$, it is rather remarkable. The calculated values by the conventional model lead to almost constant $\Delta H_{\mathrm{LS}}$ and $\Delta S_{\mathrm{LS}}$. This cannot reflect the actual situation of the change in enthalpy and entropy during solidification. For $\Delta G_{\mathrm{LS}}$, although there seems to be only a little difference, it has a remarkable effect on the nucleation kinetics. This indicates that the calculated results by traditional estimation methods can only describe the solidification process under low undercooling conditions. Only the experimental results can reveal the reality under high undercooling conditions.

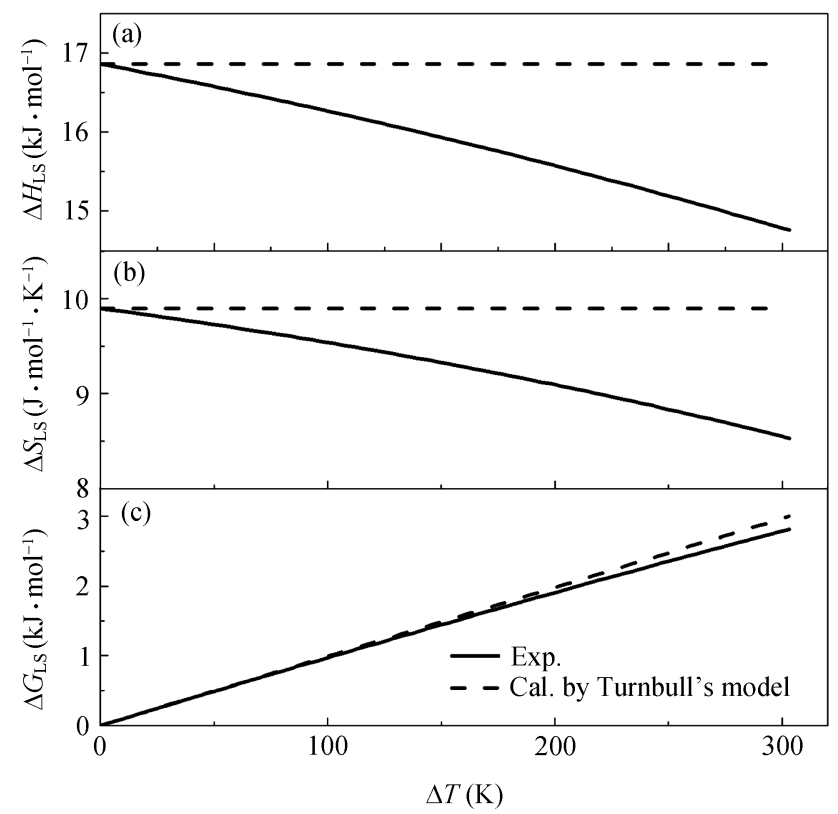

Figure 3 Calculated thermodynamic properties versus undercooling. (a) Enthalpy change; (b) entropy change; (c) Gibbs free energy difference.

\subsection{Thermal conductivity and thermal diffusivity}

Based on the experimental measurements, some other thermophysical parameters can be derived from the $C_{\mathrm{PL}}$ value. The thermal diffusivity, $\kappa$, as a function of temperature can be predicted by the following relation:

$$
\kappa=\lambda /\left(\rho \cdot C_{\mathrm{PL}}\right),
$$

where $\lambda$ is the thermal conductivity, and $\rho$ the density. Wiedemann-Franz-Lorenz law describes the relationship between thermal conductivity and electrical resistivity $\rho_{\mathrm{e}}$, which reads ${ }^{[15]}$

$$
\lambda \cdot \rho_{\mathrm{e}} / T=2.45 \times 10^{-8}\left(\mathrm{~W} \cdot \Omega \cdot \mathrm{K}^{-2}\right) .
$$

Owing to the lack of the experimental data for $\mathrm{Fe}_{77.5} \mathrm{Cu}_{13} \mathrm{Mo}_{9.5}$ alloy, its electrical resistivity is derived by Neumann-Kopps rule with the data of pure $\mathrm{Fe}, \mathrm{Cu}$ and $\mathrm{Mo}$, which is written by

$$
\rho_{\mathrm{e}}=90.8+0.013 T(\mu \Omega \cdot \mathrm{cm}) \text {. }
$$

According to eqs. (15) and (16), the thermal conductivity can be derived, which is expressed as

$$
\lambda=\frac{2.45 T}{90.8+0.013 T} \quad\left(\mathrm{~W} \cdot \mathrm{K}^{-1} \cdot \mathrm{m}^{-1}\right) .
$$


The calculated thermal conductivities are presented in Figure 4. There exists an approximately linear relation between $\lambda$ and $T$. With the increase of temperature, $\lambda$ also increases.

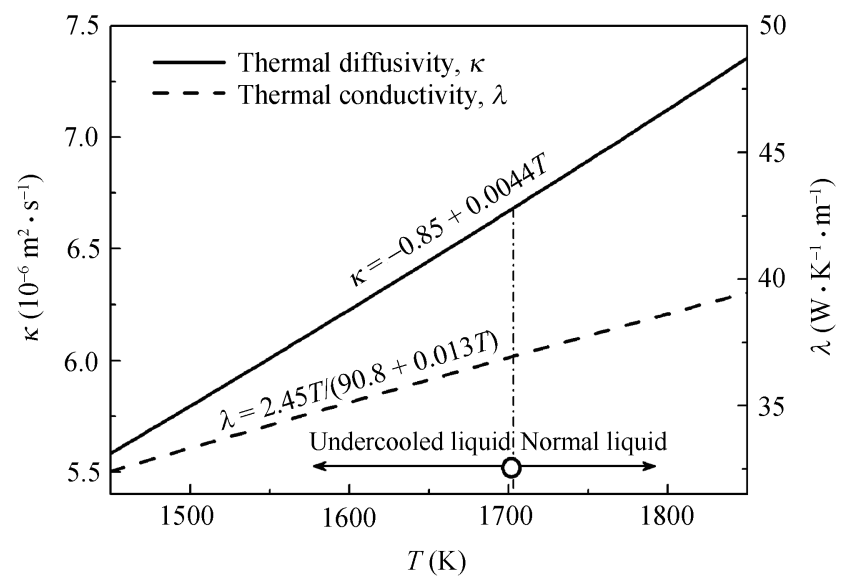

Figure 4 Thermal diffusivity and thermal conductivity versus temperature.

To obtain the thermal diffusivity, the density of $\mathrm{Fe}_{77.5} \mathrm{Cu}_{13} \mathrm{Mo}_{9.5}$ alloy is essential. The following relationship by Eötvös and Wieldeman can be employed to predict the density from surface ten$\operatorname{sion}^{[16]}$ :

$$
\sigma\left(\frac{M_{\mathrm{r}}}{\rho}\right)^{\frac{2}{3}}=K_{\mathrm{c}}\left(T_{\mathrm{c}}-T\right),
$$

where $M_{\mathrm{r}}$ is the relative atomic mass, $K_{\mathrm{c}}$ a constant equal to $6.4 \times 10^{-8}\left(\mathrm{~J} \cdot \mathrm{K}^{-1}\right)$ for liquid metals, and $T_{\mathrm{c}}$ the critical temperature at which the liquid-gas interface disappears. The surface tension of this alloy has been determined to be $\sigma=1.588-3.7 \times 10^{-4}\left(T-T_{\mathrm{m}}\right)\left(\mathrm{N} \cdot \mathrm{m}^{-1}\right)^{[17]}$. Thus, the temperature dependent density of liquid $\mathrm{Fe}_{77.5} \mathrm{Cu}_{13} \mathrm{Mo}_{9.5}$ alloy is obtained and expressed by

$$
\rho=7.5-1.49 \times 10^{-3}\left(T-T_{\mathrm{m}}\right) \quad\left(\mathrm{g} \cdot \mathrm{cm}^{-3}\right) .
$$

In terms of the results of eqs. (6), (17) and (19), the thermal diffusivity is calculated and presented in Figure 4. A linear relationship yields

$$
\kappa=-8.5 \times 10^{-7}+4.4 \times 10^{-9} T\left(\mathrm{~m}^{2} \cdot \mathrm{s}^{-1}\right) .
$$

In the governing equation for the temperature field in liquid alloys, the thermal diffusivity plays an important role in investigating their thermal history. It is always taken as a constant in traditional calculations. However, it is actually a function of temperature for the present alloy according to eq. (20). Therefore, it is essential to determine their thermophysical properties for the theoretical investigations of rapid solidification.

\subsection{Sound speed in undercooled alloy melt}

The sound speed is another important physical parameter, which is of importance in analyzing rapid crystal growth. On the basis of the density and the specific heat, the sound speed of liquid $\mathrm{Fe}_{77.5} \mathrm{Cu}_{13} \mathrm{Mo}_{9.5}$ alloy, $u$, can be predicted by ${ }^{[18]}$

$$
u=\left(\frac{1}{\rho k_{\mathrm{s}}}\right)^{1 / 2},
$$

where $k_{\mathrm{s}}$ is isentropic compressibility, which is expressed as ${ }^{[18]}$ 


$$
k_{\mathrm{s}}=\frac{\alpha^{2} V_{\mathrm{m}} T C_{\mathrm{V}}}{C_{\mathrm{PL}}\left(C_{\mathrm{PL}}-C_{\mathrm{V}}\right)},
$$

where $V_{\mathrm{m}}$ is the molar volume, $C_{\mathrm{V}}$ the specific heat at a constant volume ${ }^{[18]}$, and $\alpha$ the isobaric thermal expansivity, which is described as

$$
\alpha=-\frac{1}{\rho}\left(\frac{\partial \rho}{\partial T}\right)_{p} .
$$

Based on eqs. (6), (19), and (21)-(23), the sound speed of liquid $\mathrm{Fe}_{77.5} \mathrm{Cu}_{13} \mathrm{Mo}_{9.5}$ alloy is calculated (Figure 5). A polynomial expression between the sound speed and temperature yields

$$
u=11912-5.7 T+9.5 \times 10^{-4} T^{2}\left(\mathrm{~m} \cdot \mathrm{s}^{-1}\right) .
$$

From the above relationship, it can be seen that the sound speed decreases with the increase of temperature. In the TMK eutectic growth and LKT/BCT dendritic growth models ${ }^{[19,20]}$, the sound speed in alloy melt plays an important role. Especially, the kinetic undercooling increases steeply under a high undercooling condition. The kinetic growth coefficient is closely related to the sound speed. Previously, it is always taken as a constant in the calculation of the kinetic growth coefficient. However, it is in effect a function of temperature for the present alloy according to eq. (24).

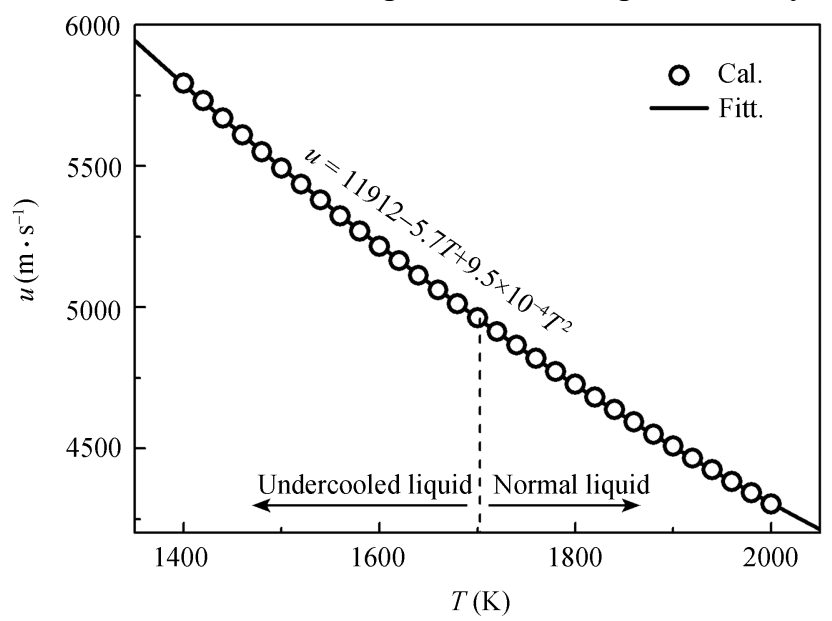

Figure 5 Sound speed in undercooled alloy melt versus temperature.

\subsection{Solidified microstructural morphology}

In order to clarify the phase constitution of the $\mathrm{Fe}_{77.5} \mathrm{Cu}_{13} \mathrm{Mo}_{9.5}$ alloy solidified at different undercoolings, XRD analysis is employed to identify the different phases, as shown in Figure 6(a). It can be seen that the as solidified samples consist of $(\mathrm{Fe})$ and $(\mathrm{Cu})$ solid solutions. Only a very tiny diffraction angle offset occurs due to the solid solubility difference inside crystal grains at different undercoolings. Usually, macrosegregation comes into being when monotectic alloys solidify due to the large density difference. In the present experiments, no remarkable macrosegregation takes place, which is effectively suppressed by the containerless processing with electromagnetic levitation.

Under equilibrium conditions, the monotectic transformation of $\mathrm{L}_{1} \rightarrow(\mathrm{Fe})+\mathrm{L}_{2}$ occurs when temperature drops to $1703 \mathrm{~K}$. If solidification takes place at low undercooling, the morphology is characterized by very coarse and well branched $(\mathrm{Fe})$ dendrites with interdendritic and intradendritic $\mathrm{L}_{2}$ phase. With the increase of undercooling, $(\mathrm{Fe})$ dendrites are refined and monotectic cells 
form. They are characterized by fine spherical or rod-like $\mathrm{L}_{2}(\mathrm{Cu})$ phases homogenously distributed in the matrix of $(\mathrm{Fe})$ phase, as shown in Figure 6(b). The $\mathrm{L}_{2}(\mathrm{Cu})$ and $(\mathrm{Fe})$ phases grow in a coupled way during the formation of monotectic cells. Generally, the second liquid $\mathrm{L}_{2}$ phase always acts as the leading phase to nucleate due to the smaller interface energy between the parent liquid phase and the second liquid phase.

In order to clarify this point of view, the interface energy of liquid/solid $\sigma_{\mathrm{LS}}$ and liquid/liquid $\sigma_{\mathrm{L}_{1} \mathrm{~L}_{2}}$ was calculated according to the interface energy model ${ }^{[21]}$, as illustrated in Figure 7. $\sigma_{\mathrm{LS}}$ increases with the increase of undercooling, whereas $\sigma_{\mathrm{L}_{1} \mathrm{~L}_{2}}$ decreases with the increase of undercooling. The $\sigma_{\mathrm{L}_{1} \mathrm{~L}_{2}}$ value is on the magnitude of $10^{-2} \mathrm{~J} \cdot \mathrm{m}^{-2}$ and much smaller than that of $\sigma_{\mathrm{LS}}$. According to the nucleation theory, the nucleation work is a function of $\sigma^{3}$, and thus, liquid-liquid nucleation work is much smaller than liquid-solid nucleation work, which is one of the most important reasons why liquid-liquid nucleation is easier than liquid-solid nucleation. Once the $\mathrm{L}_{2}(\mathrm{Cu})$ phase begins to nucleate, the local composition is favorable for the nucleation of $(\mathrm{Fe})$ phase. This results in the subsequent rapid solidification.
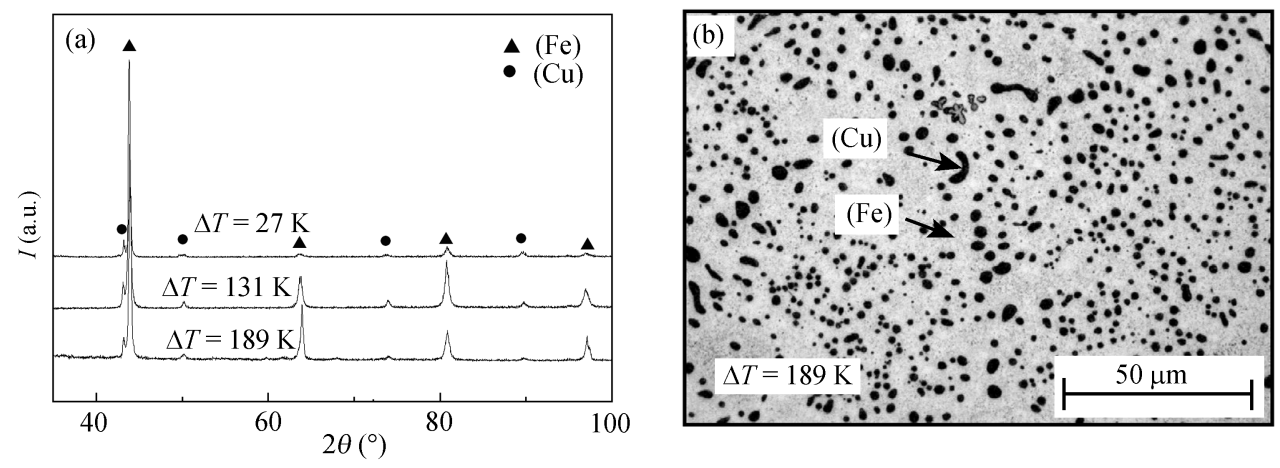

Figure 6 XRD analysis and monotectic microstructure of as solidified $\mathrm{Fe}_{77.5} \mathrm{Cu}_{13} \mathrm{Mo}_{9.5}$ alloy.

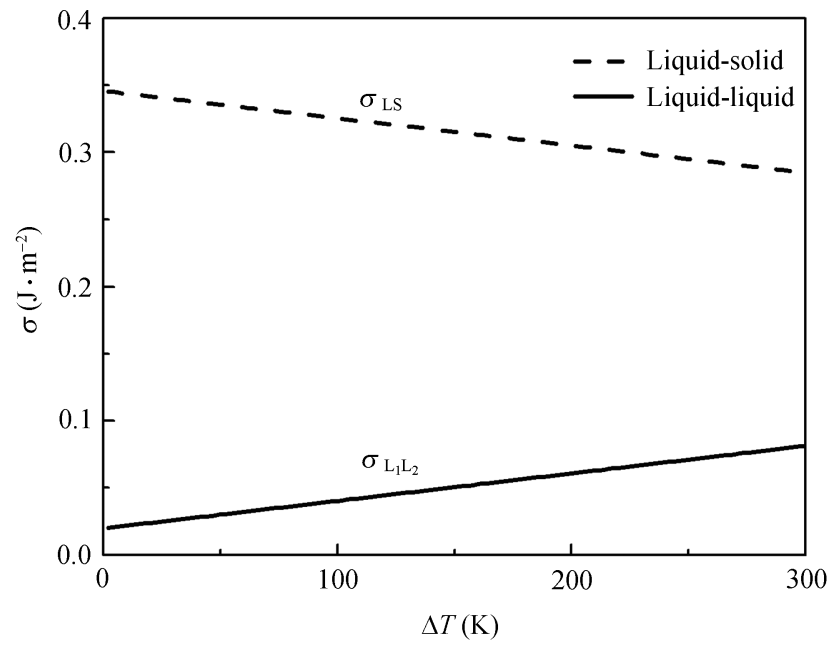

Figure 7 Interface energy versus undercooling.

\section{Conclusions}

The specific heat of undercooled liquid $\mathrm{Fe}_{77.5} \mathrm{Cu}_{13} \mathrm{Mo}_{9.5}$ monotectic alloy was measured by com- 
bining the electromagnetic levitation technique with an adiabatic drop calorimeter. A maximum undercooling of $221 \mathrm{~K}\left(0.13 T_{\mathrm{L}}\right)$ was achieved in the experiments. It was found that the enthalpy change shows an almost linear relationship within a wide temperature range from 1482 to $1818 \mathrm{~K}$ and the specific heat is determined to be $44.71 \mathrm{~J} \cdot \mathrm{mol}^{-1} \cdot \mathrm{K}^{-1}$. The excessive specific heats were calculated on the basis of experimental results and the previous theoretical models for comparison. Only the values from Dubey-Ramachandrarao's model and experimental results have the similar increasing tendency with undercooling. Furthermore, the enthalpy change, the entropy change and the Gibbs free energy difference were also calculated, and they were compared with the traditional approximate models. It was revealed that the traditional approximate values of thermodynamic properties cannot reflect the reality during the rapid solidification. Meanwhile, the other thermophysical properties, including the thermal diffusivity, thermal conductivity and sound speed, were derived according to the present experimental results. All of them are dependent on undercooling. The phase constitution and microstructure morphology were examined. XRD analysis indicates that the as solidified samples consist of $(\mathrm{Fe})$ and $(\mathrm{Cu})$ solid solutions. The interface energy of liquid/solid and liquid/liquid was calculated and employed to explain the correlation between competitive nucleation and solidification microstructure within monotectic alloy.

The authors are grateful to Mr. Qin Tao for his help with the experiments.

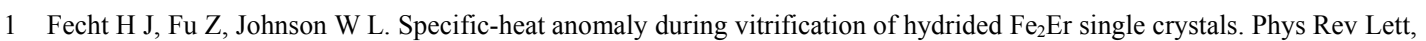
1990, 64(15): $1753-1756$

2 Sung Y S, Takeya H, Hirata K, Togano K. Specific heat capacity and hemispherical total emissivity of liquid Si measured in electrostatic levitation. Appl Phys Lett, 2003, 83(6): 1122-1124

3 Fecht H J, Perepezko J H, Lee M C, Johnson W L. Thermodynamic properties and crystallization kinetics of glass-forming undercooled liquid Au-Pb-Sb alloys. J Appl Phys, 1990, 68(9): 4494-4502

4 Wang H P, Wei B. Surface tension and specific heat of liquid $\mathrm{Ni}_{70.2} \mathrm{Si}_{29.8}$ alloy. Chin Sci Bull, 2005, 50(10): $945-949$

5 Wang N, Han X J, Wei B. Specific heat and thermodynamic properties of undercooled liquid cobalt. Appl Phys Lett, 2002, 80(1): $28-30$

6 Wang N, Wei B. Thermodynamic properties of highly undercooled liquid TiAl alloy. Appl Phys Lett, 2002, 80(19): $3515-3517$

7 Han X J, Wei B. Thermophysical properties of undercooled liquid Co-Mo alloys. Philos Mag, 2003, 83(13): 1511-1532

8 Schaefers K, Rosner-Kuhn M, Frohberg M G. Enthalpy measurements of undercooled melts by levitation calorimetry: The pure metals nickel, iron, vanadium and niobium. Mater Sci Eng A, 1995, 197(1): 83-90

9 Perepezko J H, Paik J S. Thermodynamic properties of undercooled liquid metals. J Non-Cryst Solids, 1984, 61-62(1): $113-118$

10 Ohsaka K, Gatewood J R, Trinh E H. An apparatus for the specific heat measurement of undercooled liquids. Scripta Metall Mater, 1991, 25(6): 1459-1461

11 Turnbull D. Formating of crystal nuclei in liquid metal. J Appl Phys, 1950, 21: 1022 - 1028

12 Thompson C V, Spaepen F. On the approximation of the free energy change on crystallization. Acta Metall, 1979, 27(12): $1855-1859$

13 Battezatti L, Garrone E. On the approximation of the free energy of undercooled glass-forming metallic melts. Z Metallkd, 1984, 75(2): 305-310

14 Dubey K S, Ramanchandrarao P. On the free energy change accompanying crystallization of undercooled melts. Acta Metall, 1984, 32(1): $91-96$

15 Iida T, Guthrie R I L. The Physical Properties of Liquid Metals. Oxford: Clarendon Press, 1993. 241

16 Eötvös R, Wieldeman S. Über den zusammenhang der oberfla chenspannung mit dem molekularvolumen. Ann Physik, 1886, 27(4): 448-459

17 Wang H P, Chang J, Luo B C, et al. Determination of the surface tension of liquid $\mathrm{Fe}_{77.5} \mathrm{Cu}_{13} \mathrm{Mo}_{9.5}$ ternary monotectic alloy. Chin Phys Lett, 2007, 24(2): 504-507

18 Iida T, Guthrie R I L. The Physical Properties of Liquid Metals. Oxford: Clarendon Press, 1993. 93

19 Lipton J, Kurz W, Trivedi R. Rapid dendrite growth in undercooled alloys. Acta Metall, 1987, 65(4): 957-964

20 Trivedi R, Lipton J, Kurz W. Effect of growth rate dependent partition coefficient on the dendritic growth in undercooled melts. Acta Metall, 1987, 35(4): 965-970

21 Elmer J W, Aziz M J, Tanner L E, et al. Formation of bands of ultrafine beryllium particles during rapid solidification of Al-Be alloys: Modeling and direct observations. Acta Metall Mater, 1994, 42(4): 1065 - 1080 